\title{
Protetor físico associado à semeadura direta de espécies vegetais nativas em área de Floresta Ombrófila Mista em processo de restauração
}

\author{
Isabela Giordani, Adriano Dias de Oliveira, CAmila KissmanN ${ }^{\dagger}$ \\ camilakissmann@gmail.com
}

\begin{abstract}
Resumo
A semeadura direta é uma técnica barata e de fácil implantação utilizada para a restauração de áreas degradadas que pode ser otimizada com o uso de protetores físicos. Este trabalho foi desenvolvido com o objetivo de avaliar a eficiência dos protetores físicos associados à semeadura direta na emergência, crescimento inicial e sobrevivência de plântulas de Parapiptadenia rigida (Benth.) Brenan, Eugenia uniflora L. e Eugenia involucrata DC. Os tratamentos consistiram de presença e ausência de protetores físicos (garrafas PET), sendo utilizados 24 pontos de semeadura para cada espécie em cada condição experimental. A emergência foi avaliada mensalmente a partir dos 15 dias até seis meses após a semeadura, o crescimento inicial foi avaliado mensalmente durante seis meses e a sobrevivência das plântulas, no sexto mês após a semeadura. Os dados de emergência, crescimento e sobrevivência das plântulas e os dados climáticos foram comparados por teste $t$ de Student $(\mathrm{p}<0.05)$. A emergência e o crescimento inicial das plântulas das três espécies estudadas foram favorecidas pelo uso de protetores físicos. Entretanto, a sobrevivência nos pontos com protetor físico só foi superior ao controle para as plantas de E. uniflora.

Palavras chaves: Áreas degradadas, emergência, crescimento inicial, sobrevivência
\end{abstract}

\begin{abstract}
Direct sowing is a cheap and easy to use technique applied for the restoration of degraded areas that can be optimized with the use of physical protector. This study was carried out with the objective of evaluate the efficiency of physical protectors associated with direct sowing in emergency, early growth and survival of Parapiptadenia rigida (Benth.) Brenan, Eugenia uniflora L. and Eugenia involucrata DC. seedlings. The treatments consisted in the presence and absence of physical protectors (PET bottles), being used 24 points of sowing to each species for each experimental condition. The emergency was evaluated monthly from 15 days up to six months after sowing, the initial growth was evaluated monthly during six months and the survival of seedlings at the sixth month after sowing. Data of emergency, seedling initial growth and survival and climate data were compared by Student's $t$ test $(p<0.05)$. The emergence and early growth of seedlings of all species were favored by the use of physical guards. However, survival in points with physical guard was only superior than the control for the E. uniflora seedlings.

key words: Degraded areas, emergence, initial growth, survival.

\footnotetext{
*Curso de Ciências Biológicas, Universidade Comunitária da Região de Chapecó. Avenida Senador Atílio Fontana,

${ }^{\dagger}$ Universidade Estadual Paulista Júlio de Mesquita Filho, Campus de Botucatu, Instituto de Biociências. Rua Prof. Dr.
} 591E, 89809-000, Chapecó, SC, Brasil. Antonio Celso Wagner Zanin, s/nº, 18618-970, Botucatu, SP, Brasil.
\end{abstract}




\section{INTRODUÇÃO}

A Tualmente o Bioma Mata Atlântica encontra-se altamente fragmentado sendo que mais de $80 \%$ dos seus fragmentos possuem área inferior a 50 hectares (RIBEIRO et al., 2009). No Estado de Santa Catarina, que aparece em terceiro lugar no ranking de Estados com maior histórico de desmatamento (SOS MATA ATLÂNTICA, 2015) a degradação das florestas ocorreu, sobretudo, em consequência da extração e comércio de madeira (SEVEGNANI e SCHROEDER, 2013). Em Santa Catarina o bioma abrange três tipologias florestais: a Floresta Ombrófila Densa (FOD), a Floresta Ombrófila Mista (FOM) e a Floresta Estacional Decidual (FED) (PROCHNOW, 2008). A FOM é caracterizada pela presença dominante de Araucaria angustifolia (pinheiro-doparaná) no dossel (KLEIN, 1960), sob o qual se desenvolvem outras espécies, com predominância das famílias Myrtaceae, Fabaceae e Lauraceae (JARENKOW e BUDKE, 2009). A intensa fragmentação desta fisionomia florestal foi reportada pelo Inventário Florístico Florestal de Santa Catarina (VIBRANS, 2013a), onde se constatou que mais de $80 \%$ dos seus fragmentos remanescentes possuem uma área de até 50 hectares (VIBRANS et al., 2013b). Além disso, foram observadas baixas riqueza e abundância de algumas espécies bem como baixas taxas ou ausência de regeneração natural nos fragmentos remanescentes de FOM amostrados no IFFSC (VIBRANS et al., 2013b), o que denota a necessidade de conservação e restauração destes remanescentes.

Dentre os métodos de restauração propostos pela comunidade científica no atual contexto destaca-se a semeadura direta, por ser um método econômico e de fácil implantação, caracterizada pelo plantio direto das sementes. Essa técnica pode ser utilizada tanto para a introdução de espécies pioneiras em áreas que não possuem cobertura vegetal (RODRIGUES et al., 2009) quanto para a introdução de espécies secundárias ou clímax para enriquecimento de áreas com florestas secundárias (KAGEYAMA e GANDARA, 2004). Contudo, o sucesso deste método pode ser limitado pelo fato de a emergência e o crescimento inicial das plântulas representarem períodos críticos para a sobrevivência dos vegetais (LARCHER, 2000). Durante a germinação e o desenvolvimento pós-embrionário inicial da plântula (após a protrusão da radícula) o desenvolvimento do embrião se faz, a princípio, heterotroficamente à custa das reservas contidas no endosperma ou nos cotilédones, porém, uma vez esgotadas essas reservas, a plântula passa a depender dos recursos do meio (solo e atmosfera) para sobreviver. De fato, Meneghello e Mattei (2004) observaram que as maiores perdas de plantas das espécies florestais Enterolobium contortisiliquum (Vell.) Morong, Peltophorum dubium (Spreng.) Taub. e Cedrela fissilis Vell. ocorrem nos primeiros 30 dias após a semeadura direta em campos abandonados.

Uma alternativa utilizada para minimizar este problema é a otimização do estabelecimento e crescimento das plântulas com o uso de protetores físicos associados à semeadura (MATTEI e ROSENTHAL, 2002; FERREIRA et al., 2007), os quais contribuem para a formação de um microclima com temperatura e umidade mais favoráveis à germinação, ao crescimento e a sobrevivência das plantas, além de fornecer proteção física contra predadores e evitar o soterramento das sementes (MATTEI, 1997). Assim, o uso de protetores físicos pode ser uma alternativa viável e de baixo custo que otimiza o sucesso da técnica de semeadura direta para algumas espécies vegetais. Entretanto, observase na literatura que a contribuição do uso de protetores na emergência, crescimento e estabelecimento das mudas varia entre as espécies (MENEGHELLO e MATTEI, 2004; FERREIRA et al., 2007; SILVA et al., 2012) havendo a necessidade de mais estudos para ampliar o conhecimento neste sentido.

Diante do atual quadro de degradação das formações florestais, a restauração de áreas degradadas assume papel essencial para a manutenção da diversidade biológica e do equilíbrio ecossistêmico. A recuperação destes hábitats demanda estudos com o intuito de viabilizar e aprimorar as técnicas de restauração a fim 
de que possam ser utilizadas com sucesso para diferentes espécies e locais. Nesse contexto, o presente trabalho teve como objetivo avaliar a eficiência do uso de protetores físicos associados à semeadura direta na emergência, crescimento inicial e sobrevivência de mudas de três espécies arbóreas com ocorrência na FOM, pertencentes a diferentes grupos sucessionais: i) Parapiptadenia rigida (Benth.) Brenan (Fabaceae), uma espécie secundária inicial que apresenta crescimento rápido, conhecida popularmente como angico-vermelho; ii) Eugenia uniflora L. (Myrtaceae), uma espécie pioneira, conhecida popularmente como pitanga; e iii) Eugenia involucrata DC. (Myrtaceae), secundária tardia, conhecida como cereja ou cerejeira (MEYER et al., 2013).

\section{Metodologia}

\section{Área de estudo}

O estudo foi realizado na Estação Ecológica da Mata Preta (ESEC da Mata Preta) $\left(26^{\circ} 28^{\prime} 17.85^{\prime \prime}\right.$ e $52^{\circ} 9^{\prime} 34.99^{\prime \prime}$ ), localizada no Município de Abelardo Luz, no noroeste do Estado de Santa Catarina, que faz limite com os municípios de Palmas e Clevelândia, no Estado do Paraná (Figura 1). A área a ser restaurada foi indenizada pelo governo federal em 2012, após ser utilizada para lavoura durante vários anos, e passou a integrar a Unidade de Conservação ESEC da Mata Preta, que conta com uma área total de 6.563 hectares dividida em três fragmentos (ICMBIO, 2013).

O clima na região da ESEC da Mata Preta é o Cfb (classificação de Köppen) do tipo subtropical temperado, sem estação seca, com temperatura média nos meses de junho e julho inferior a $18^{\circ} \mathrm{C}$ e temperatura média nos meses mais quentes, janeiro e fevereiro, inferior a $22^{\circ} \mathrm{C}$. Os verões são brandos e os invernos são frios, com geadas frequentes; as chuvas são distribuídas por todos os meses do ano (ALVARES et al., 2013).

\section{Material vegetal}

A escolha das espécies foi baseada na lista de espécies presentes no Plano de Proteção da ESEC da Mata Preta. As sementes de E. uniflora e E. involucrata foram obtidas de frutos maduros de três matrizes diferentes no município de Xaxim, Santa Catarina. As sementes de P. rigida foram fornecidas pelo Laboratório de Sementes da Universidade Comunitária da Região de Chapecó - Unochapecó, as quais estavam armazenadas por um período de dois meses sob condições controladas de temperatura e umidade. As sementes de cada espécie (lote) foram caracterizadas quanto ao teor de umidade e desempenho germinativo no Laboratório de Sementes da Unochapecó. A umidade de cada lote foi determinada pelo método gravimétrico (estufa a $105^{\circ} \mathrm{C}$ até obtenção de massa constante) de acordo com as Regras para Análises de Sementes (BRASIL, 2009) com três repetições de 50 sementes para cada espécie.

\section{Desenho experimental}

A semeadura das três espécies na ESEC da Mata Preta foi realizada em novembro de 2015. Para a semeadura de cada espécie foram demarcadas quatro parcelas de $24 \mathrm{~m}^{2}$ com 12 pontos de semeadura por parcela, com espaçamento de $2 \mathrm{~m}$ entre os pontos. No total, foram demarcadas doze parcelas na área, sendo as parcelas de cada espécie distribuídas sistematicamente com alternância entre as espécies e distância de $5 \mathrm{~m}$ entre as parcelas. O experimento foi realizado com 48 pontos de semeadura por espécie.

Dentro de cada parcela, os tratamentos, constituídos de presença e ausência de protetores físicos no local de semeadura, foram distribuídos de forma alternada, sendo 50\% dos pontos de semeadura com presença de protetores físicos e 50\% sem a utilização de protetores. Os protetores físicos foram confeccionados com garrafas de politereftalato de etileno (PET) transparentes com capacidade de 2 1 , as quais tiveram as partes superior e inferior removidas (18 $\mathrm{cm}$ de altura). Para assegurar a emergência e a disponibilidade de plântulas e 


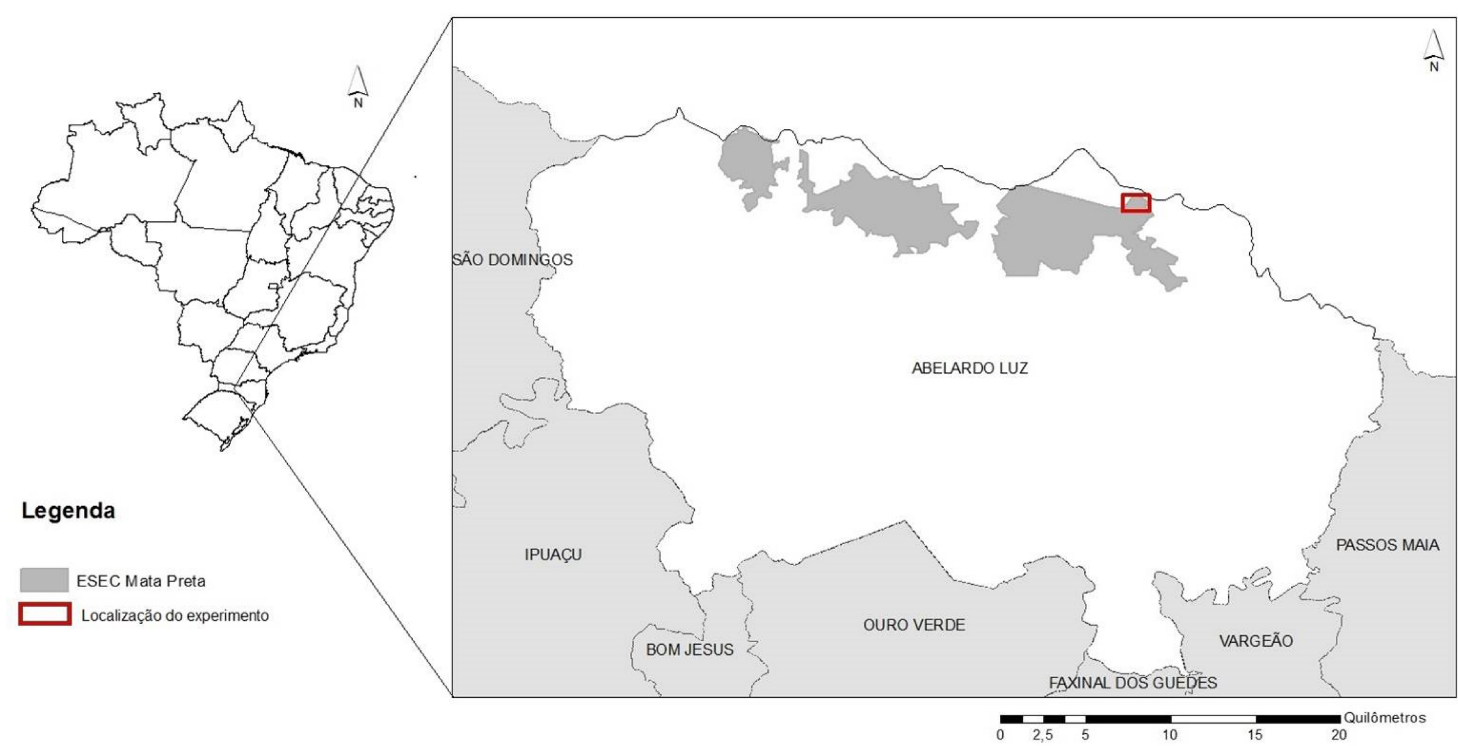

Figura 1: Mapa da localização da Estação Ecológica da Mata Preta, com destaque para a área onde foi realizado o experimento, localizada no município de Abelardo Luz, SC.

mudas para o estudo foram alocadas três sementes por cova a $5 \mathrm{~cm}$ de profundidade. A emergência das sementes foi verificada a cada 30 dias após a semeadura (DAS) e, havendo a emergência de mais de uma semente, as plântulas excedentes foram removidas para evitar competição.

\section{Coleta e análise de dados}

O experimento de semeadura direta estendeu-se por seis meses, de novembro de 2015 a maio de 2016, sendo avaliados durante este período, a cada 30 dias a partir de 15 dias após a semeadura (DAS), a emergência e o crescimento inicial das plântulas, e, ao final do experimento (195 DAS), a taxa sobrevivência das plantas. A emergência das plântulas foi avaliada pela contagem de sementes que apresentaram desenvolvimento acima da superfície do solo e o crescimento inicial das mudas foi avaliado pela medição da altura (medida desde o coleto até o meristema apical) e diâmetro do coleto. Os valores da altura e do diâmetro foram obtidos com o uso de régua graduada e paquímetro digital, respectivamente.
Durante o experimento foram obtidos mensalmente dados de temperatura e umidade do ar, com o uso de um mini medidor multifuncional Instrutemp ITSP 8001, em cinco pontos com presença e cinco com ausência de protetores físicos, os quais foram escolhidos ao acaso. A determinação da umidade do solo nos pontos com presença e ausência de protetores físicos foi realizada a cada 30 dias, por meio da coleta de cerca de 20 gramas de solo, em cinco pontos de cada condição. A umidade do solo foi determinada pela diferença entre o peso úmido e peso seco das amostras, após serem submetidas a um período de 24 horas em estufa a $105^{\circ} \mathrm{C}$, e expressa em porcentagem. Os dados de emergência das plântulas, crescimento das mudas (altura e diâmetro) e sobrevivência foram avaliados por meio do Teste t de Student, ambos ao nível de 5\% de significância. Os dados climáticos (umidade do solo e do ar e temperatura) foram comparados por teste $t$ de Student $(p<0.05)$. 


\section{Resultados}

As sementes de E. uniflora e E. involucrata apresentaram teores de umidade de 57,9 e $54,8 \%$, respectivamente. Esses valores são considerados elevados em comparação às sementes de $P$. rigida que apresentaram teor de umidade de $14,4 \%$. O uso de protetor físico favoreceu a emergência das plântulas das três espécies (Figura 2). As sementes de P. rigida expressaram todo o seu potencial germinativo dentro de 45 dias, não havendo variação na emergência após este período (Figura 2A). Já para as espécies de Eugenia, a emergência ocorreu mais lentamente, distribuindo-se ao longo do período experimental, sendo possível detectar diferenças no uso dos protetores a partir dos 75 dias após a semeadura (Figuras 2B, 2C) para ambas as espécies. As sementes de P. rigida apresentaram emergência a partir de 15 dias após a semeadura em ambos os tratamentos (com e sem protetor físico) enquanto que a emergência das plântulas das sementes de ambas as espécies de Eugenia com o uso do protetor só foi observada dos 45 DAS e sem o uso do protetor aos 135 DAS (Figura 2B, 2C).

Foram observadas diferenças significativas no crescimento das plântulas em altura e diâmetro entre os tratamentos (Figura 3). As plântulas de $P$. rigida desenvolvidas nos pontos com protetor físico apresentaram crescimento em altura e diâmetro superior ao observado para as plântulas crescidas sem os protetores durante todo o período do experimento (Figura 3A, 3B), porém só foi observada diferença no diâmetro no início do crescimento das mudas (Figura 3B), dos 15 aos 75 dias após a semeadura. A partir deste período observa-se uma redução nos valores de diâmetro que ocorreu em consequência da mortalidade de plântulas (Figura 3B e Tabela 1). O crescimento em altura e diâmetro de E. uniflora foi superior nos pontos com protetor físico desde os 75 DAS até o final do experimento, aos 195 DAS (Figura 3C, 3D). Para E. involucrata, houve diferença significativa entre os tratamentos, sendo o crescimento das plântulas, tanto em altura quanto em diâmetro, superior nos pontos com protetor físico entre 75 e 135 DAS (Figura 3E, 3F).

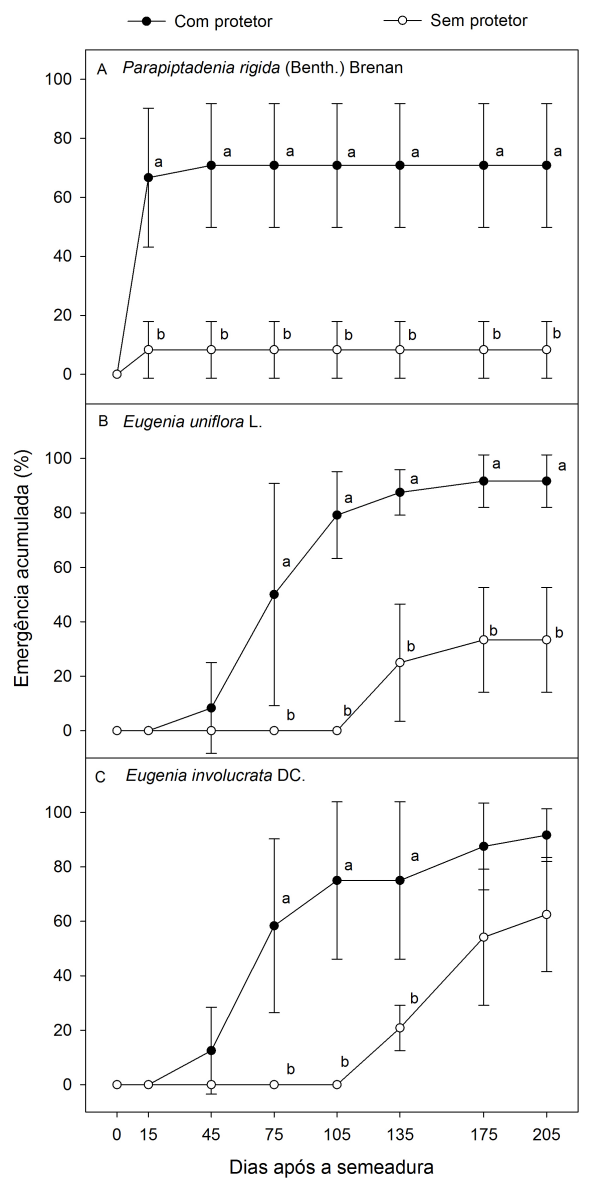

Figura 2: Emergência acumulada de plântulas de Parapiptadenia rigida (Benth.) Brenan, Eugenia uniflora L. e Eugenia involucrata DC. provenientes de semeadura direta. Letras distintas indicam diferença estatística entre as médias pelo teste t de Student $(p<0.05)$ e a ausência de letras indica ausência de diferença significativa entre os tratamentos. Os pontos representam os valores médios e as barras representam o desvio padrão.

A sobrevivência de $P$. rigida não diferiu em função dos tratamentos $(\mathrm{t}=1.41 ; \mathrm{P}=0.207)$ sendo observada sobrevivência de $21 \%$ no tratamento com protetor e ausência de plântulas vivas no tratamento sem protetor (Tabela 1 ). A sobrevivência das plântulas emergidas, aos seis meses após a semeadura, diferiu nos pontos com e sem protetor somente para a espécie 
E. uniflora, sendo a sobrevivência superior nos pontos com protetor físico $(\mathrm{t}=6.928 ; \mathrm{P}=<0.001)$ - Já para E. involucrata foi elevada (superior a $70 \%)$ e não diferiu entre os tratamentos ( $t=$ 0.600; $\mathrm{P}=0.570$ ) (Tabela 1).

Ao longo do experimento foi observada variação nos parâmetros abióticos de temperatura e umidade do ar nos pontos de semeadura com presença e ausência de protetores físicos. Nos meses de janeiro, fevereiro e abril a temperatura nos pontos com protetor foi maior em relação aos pontos sem protetor (Figura 4A). Nos pontos com protetor também foi observada maior umidade do ar ao longo do experimento, exceto para a avaliação realizada no mês de março (Figura 4B). A umidade do solo não apresentou diferenças significativas entre os tratamentos (Figura 4B).

\section{Discussão}

O uso de protetores físicos confeccionados com garrafas plásticas transparentes (PET) apresentou efeitos distintos em função dos parâmetros avaliados - emergência, crescimento e sobrevivência das plântulas - e da espécie considerada. A emergência das três espécies estudadas foi favorecida pela presença dos protetores. No caso de P. rigida, tanto as sementes protegidas como aquelas não protegidas expressaram o seu potencial germinativo dentro de um período de 15 dias.

Para as sementes das espécies das duas espécies de Eugenia o uso de protetores físicos além de propiciar maior emergência também influenciou positivamente o tempo de emergência das plântulas. As plântulas emergiram mais cedo nos pontos com protetores, sendo observada diferença de 90 dias na emergência entre os tratamentos com e sem protetor (Figura 2A e 2B). Nesse contexto, a redução no tempo de emergência das plântulas é uma vantagem pois, reduz o tempo de exposição das sementes aos fungos e outros microrganismos do solo que podem levar à perda de viabilidade (LEISHMAN et al., 2000).

No caso das espécies de Eugenia, a redução no tempo de emergência observada com o uso de protetores, é especialmente vantajosa devido ao comportamento recalcitrante de suas sementes (DELGADO e BARBEDO, 2007). As sementes recalcitrantes são dispersas com elevado teor de água e devido a isso, apresentam curta longevidade após a dispersão (ROBERTS, 1973). Já as sementes ortodoxas, como as de $P$. rigida, passam pela fase de dessecação ao final do seu desenvolvimento, e são dispersas com baixo teor de água e metabolismo reduzido, o que prolonga a sua viabilidade, podendo ser armazenadas por longos períodos (ROBERTS, 1973). No caso de E. uniflora e E. involucrata, as sementes são sensíveis à redução do teor de água para valores inferiores a $45 \%$ e perdem a viabilidade quando o teor de água encontra-se entre 15 a 20\% (DELGADO e BARBEDO, 2007). Apesar da maior umidade do ar registrada dentro dos protetores físicos, estes não foram suficientes para assegurar maior umidade do solo de modo que um longo período no solo poderia resultar na perda de viabilidade das sementes recalcitrantes de Eugenia.

Neste trabalho, o uso do protetor favoreceu a emergência de E. involucrata, uma espécie secundária tardia, corroborando os resultados observados para outras espécies tardias (SANTOS JUNIOR, 2000). Já para as espécies crescimento rápido, como $P$. rigida, Ferreira et al. (2007) considera o uso dos protetores físicos dispensável. No presente estudo, as sementes de $P$. rigida apresentaram emergência de $70 \%$ nos pontos com presença dos protetores físicos e $10 \%$ nos pontos sem protetores. Esses dados evidenciam que as respostas de emergência das plântulas às condições microclimáticas proporcionadas pelo uso do protetor variam entre as espécies e não podem ser generalizadas para os grupos ecológicos.

Devido à natureza lipídica e proteica das células e das organelas celulares e, considerando que o metabolismo é essencialmente uma sequência de reações bioquímicas, a temperatura tem uma grande influência sobre os processos essenciais ao crescimento e desenvolvimento dos vegetais, tais como absorção de água e nutrientes, fotossíntese e respiração (LARCHER, 2000). No presente trabalho, o uso 


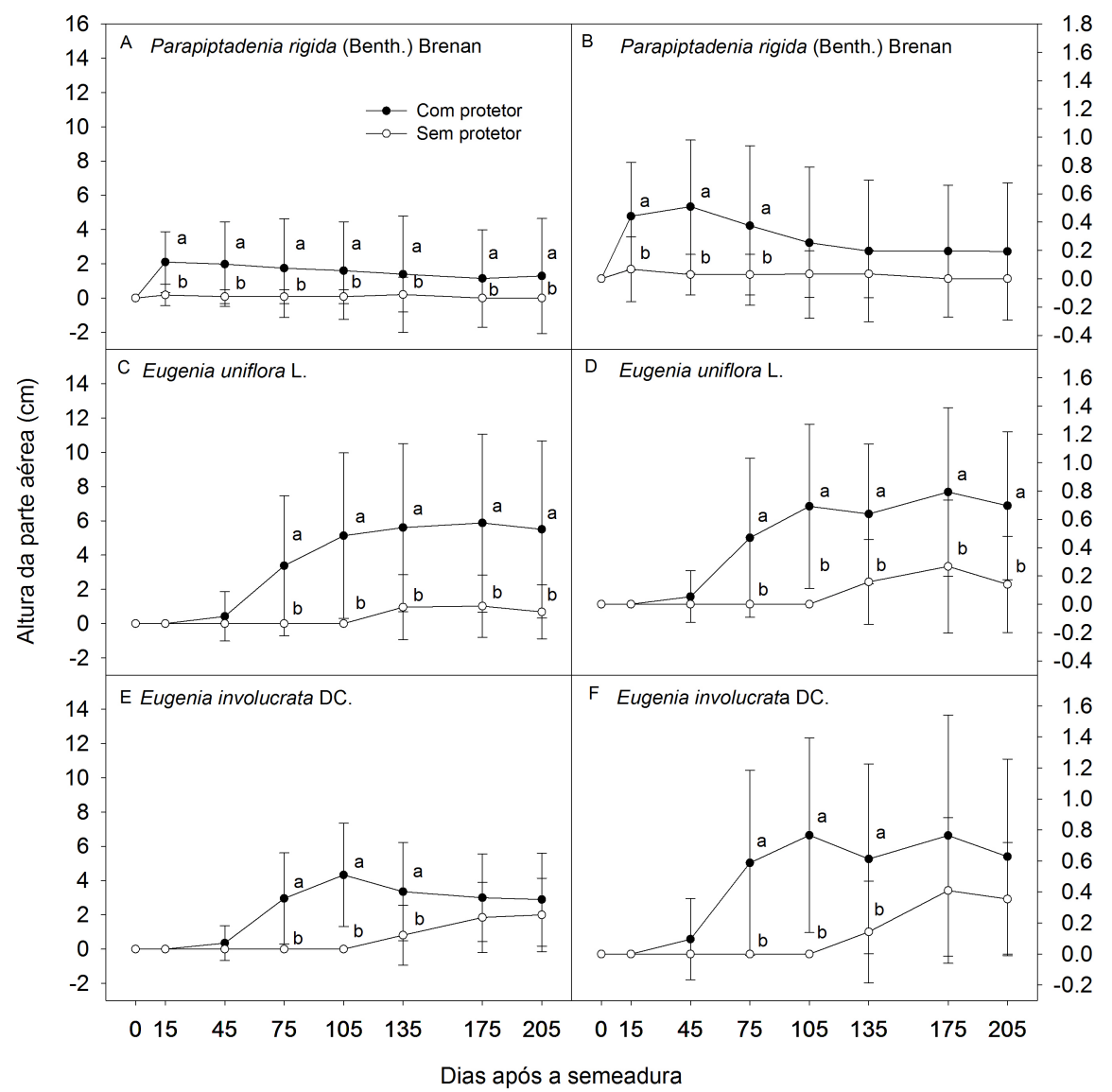

Figura 3: Crescimento em altura e diâmetro de plântulas Parapiptadenia rigida (Benth.) Brenan, Eugenia uniflora L.e Eugenia involucrata DC, provenientes de semeadura direta. Letras distintas indicam diferença estatística entre as médias pelo teste t de Student $(p<0.05)$ e a ausência de letras indica ausência de diferença significativa entre os tratamentos. Os pontos representam os valores médios e as barras representam o desvio padrão.

de protetores físicos resultou no aumento da temperatura e, consequentemente, em maior crescimento em altura e diâmetro das plântulas nestas condições, especialmente no caso de $E$. uniflora, conferindo-lhes vantagens competitivas.

O maior crescimento das plântulas de Eugenia no tratamento com protetores físicos, em parte, é uma consequência da idade destas plantas uma vez que dentro dos protetores a emergência ocorreu mais cedo do que nos pontos sem protetores. Ainda assim, quando comparamos plantas com a mesma idade (tempo após emergência) observa-se que as plântulas desenvolvidas na ausência de protetores tive- ram crescimento reduzido. Os benefícios do protetor físico no crescimento inicial das plântulas variam de acordo com a espécie, inclusive dentro do mesmo gênero. Ferreira et al. (2007) observaram maior altura e diâmetro do colo em mudas de Senna multijuga (Rich.) Irwin et Barn. e maior altura de mudas de Senna macranthera (Collad.) Irwin et Barn. provenientes de semeadura com o uso de protetor físico em relação à semeadura sem protetor físico. Entretanto, outra espécie do mesmo gênero, Senna pendula (Willd.) H.S.Irwin \& Barneby, não apresentou variação na altura das mudas nos tratamentos com presença e ausência de protetores físicos (SILVA et al., 2012). 


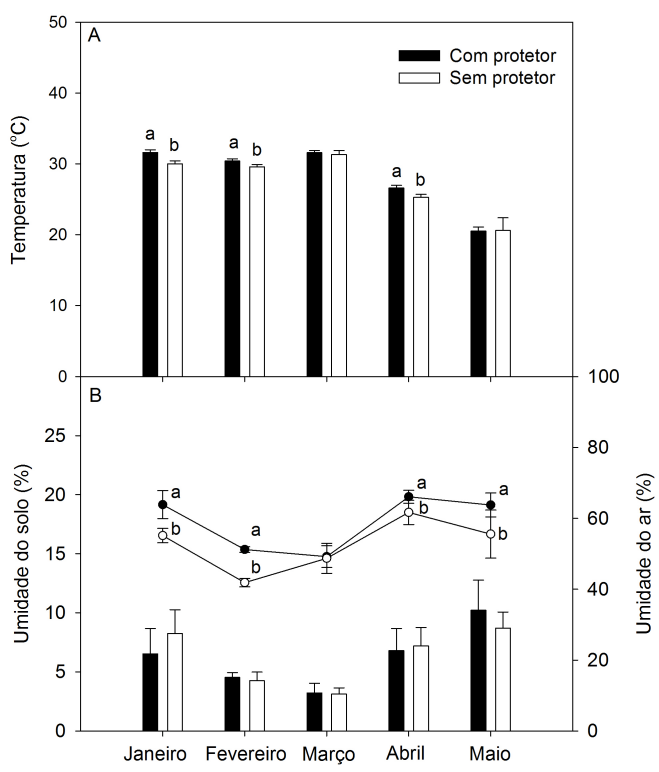

Figura 4: Temperatura (A) e umidade do solo (barras) $e$ do ar (linhas) (B) registradas nos meses de janeiro a maio de $2016 \mathrm{em}$ pontos com presença e ausência de protetor físico, na ESEC da Mata Preta $(n=5)$. Abelardo Luz, SC, 2016. Letras distintas indicam diferença estatística entre as médias pelo teste $t(p<0.05)$ e a ausência de letras indica ausência de diferença significativa entre os tratamentos. Os pontos e colunas representam os valores médios e as barras representam o desvio padrão.

A redução observada na altura da parte aérea das plântulas e do diâmetro das plântulas ao final do estudo é resultado da ação de herbívoros. A predação pode causar danos tanto na fase de sementes quanto de plântulas. Danos causados por formigas e outros insetos são observados mesmo quando a semeadura é realizada com o uso de protetores físicos, pois, por apresentarem as extremidades abertas, estes não constituem barreiras contra a ação destes predadores (MATTEI e ROSENTHAL, 2002).

Além do efeito no crescimento, os protetores físicos podem contribuir para a sobrevivência das plântulas, como observado para as plântulas de E. uniflora neste trabalho. Tal efeito foi também observado para as espécies Cedrela fissilis Vell e Sapindus saponaria L., que apresentaram maior sobrevivência nos pontos com protetores físicos (MENEGHELLO e MATTEI, 2004; SANTOS, 2012). Entretanto, neste estudo, a sobrevivência de E. involucrata e $P$. rigida não foi influenciada pelo o uso de protetor, corroborando o observado para diversas outras espécies florestais (MATTEI e ROSENTHAL, 2002; MENEGHELLO e MATTEI, 2004; FERREIRA et al., 2007). A sobrevivência das plântulas pode estar relacionada a diversos fatores, dentre eles, ao tamanho das sementes utilizadas na semeadura direta uma vez que as sementes maiores possuem mais reservas energéticas acumuladas, necessárias para o desenvolvimento das plântulas (FERREIRA et al., 2009). Neste estudo, as plântulas de E. uniflora e E. involucrata apresentaram sobrevivência superior às plântulas de $P$. rigida (Tabela 1 ) e as sementes destas espécies também apresenta tamanho superior em relação à esta última, conforme pode ser observado pelo peso de mil sementes, que é de $0,420 \mathrm{~kg}$ para E. uniflora, $0,133 \mathrm{~kg}$ para $E$. involucrata e $0,025 \mathrm{~kg}$ para $P$. rigida (LORENZI, 1992). Ferreira et al. (2009) também reportaram que o sucesso na sobrevivência de mudas provenientes de semeadura direta é influenciado pelo tamanho das sementes.

As plântulas de $P$. rigida apresentaram baixa sobrevivência mesmo com o uso de protetores físico. Considerando que a espécie apresenta rápido crescimento, tal fato pode estar relacionado à maior exigência nutritiva que as espécies iniciais apresentam em relação às espécies tardias em função deste fator (SILVA e MUNIZ, 1995). Assim, é possível que a elevada mortalidade destas plântulas esteja relacionada às condições nutricionais do solo, porém, este aspecto não foi contemplado no presente estudo. As plântulas de E. involucrata, ao contrário, apresentaram elevada sobrevivência mesmo na ausência dos protetores.

\section{Conclusão}

Diante dos resultados obtidos neste estudo, conclui-se que o uso de protetores físicos do tipo PET associado à semeadura direta é eficaz para otimizar a emergência, o crescimento e a sobrevivência das plântulas de Eugenia uniflora. 
Tabela 1: Sobrevivência das plântulas de Parapiptadenia rigida (Benth.) Brenan, Eugenia uniflora L. e Eugenia involucrata DC. avaliadas aos seis meses após a semeadura na ESEC da Mata Preta. Abelardo Luz, SC. 2015/2016.

\begin{tabular}{lcc}
\hline & & Sobrevivência (\%) \\
\hline & Com protetor & Sem protetor \\
Parapiptadenia rigida (Benth.) Brenan & $21 \pm 30$ & 0 \\
Eugenia uniflora L. & $91 \pm 9 \mathrm{a}$ & $44 \pm 28 \mathrm{~b}$ \\
Eugenia involucrata DC. & $73 \pm 28$ & $87 \pm 19$ \\
\hline
\end{tabular}

Letras distintas indicam diferença estatística entre as médias pelo teste $t(p<0.05)$ e a ausência de letras indica ausência de diferença significativa entre os tratamentos. Os valores indicam as médias seguidas do desvio padrão.

Para Eugenia involucrata e Parapiptadenia rigida o uso do protetor físico não é necessário uma vez que a sobrevivência das plântulas não diferiu entre os tratamentos com ausência e presença do protetor.

\section{Agradecimentos}

Os autores agradecem ao ICMBio pela autorização da pesquisa e a Unochapecó pelo apoio à pesquisa. Isabela Giordani agradece ao Conselho Nacional de Desenvolvimento Científico e Tecnológico (CNPq) pela concessão da bolsa de Iniciação Científica.

\section{REFERÊNCIAS}

ALVARES, C.A.; STAPE, J.L.; SENTELHAS, P.C.; GONÇALVES, J.L.; SPAROVEK, G. Köppen's climate classification map for Brazil Meteorologische Zeitschrift, Stuttgart, v.22, p. 711-728, 2013.

BRASIL - MINISTÉRIO DA AGRICULTURA E REFORMA AGRÁRIA. Regras para análise de sementes MAPA/ACS, Brasília, 399p., 2009.

DELGADO, L.F.; BARBEDO, C.J. Tolerância à dessecação de sementes de espécies de $\mathbf{E u}$ genia Pesquisa Agropecuária Brasileira, Brasília, v.42, n. 2, p. 265-272, 2007.

FERREIRA, R.A.;, DAVIDE, A.C.; BEARZOTI, E.; MOTTA, M.S. Semeadura direta com espécies arbóreas para recuperação de ecossistemas florestais Cerne, Lavras, v.13, p. 271-279, 2007.

FERREIRA, R.A.; SANTOS, P.L.; ARAGÃO, A.G.; SANTOS, T.I.S.; NETO, E.M.; REZENDE, A.M. Semeadura direta com espécies florestais na implantação de mata ciliar no Baixo São Francisco em Sergipe Scientia Forestalis, Piracicaba, v.37, n. 81, p37-46, 2009.

ICMBIO - INSTITUTO CHICO MENDES DE CONSERVAÇÃO DA BIODIVERSIDADE. Plano de Proteção - Estação Ecológica Mata $<$ http//www.icmbio.gov.br $>$, Acesso em 17 de Maio de 2015.

JARENKOW, J.A.; BUDKE, J.C. Padrões florísticos e análise estrutural de remanescentes de Florestas com Araucária no Brasil In: FONSECA, C.R.; SOUZA, A.F.; LEALZANCHET, A.M.; DUTRA, T.; BACKES, A.; GANADE, G (Orgs.) Floresta com araucária: ecologia, conservação e desenvolvimento sustentável, Holos Editora, Ribeirão Preto, p. 113-126, 2009.

KAGEYAMA P.Y.; GANDARA, F.B. Recuperação de áreas ciliares In: RODRIGUES, R.R.; LEITÃO FILHO, H.F. (Ed.)Matas ciliares: conservação e recuperação, Edusp/Fapesp, São Paulo, p. 249-269, 2004.

KLEIN, R.M. O aspecto dinâmico do pinheiro brasileiro Sellowia, Itajaí, v.12, p. 17$44,1960$. 
LARCHER, W. Ecofisiologia vegetal Rima, São Carlos, 531p., 2000.

LEISHMAN, M.R.; MASTERS, G.J.; CLARKE, I.P.; BROWN, V.K. Seed bank dynamics: the role of fungal pathogens and climate change Functional Ecology, London, v.14, p. 293-299, 2000.

LORENZI, H. Árvores brasileiras: manual de identificação e cultivo de plantas arbóreas nativas do Brasil Plantarum, Nova Odessa, 352p., 1992.

MATTEI, V.L. Avaliação de protetores físicos em semeadura direta de Pinus taeda L. Ciência Florestal, Santa Maria, v.7, p. 91-100, 1997.

MATTEI, V.L.; ROSENTHAL, M.D. Semeadura direta de canafístula (Peltophorum dubium (Spreng.) Taub. no enriquecimento de capoeiras Revista Árvore, Viçosa, v.26, n.6, p. 649-654, 2002.

MENEGHELLO, G.E.; MATTEI, V.L. Semeadura direta de timbaúva (Enterolobium contortisiliquum), canafístula (Peltophorum dubium) e cedro (Cedrela fissilis) em campos abandonados Ciência Florestal, Santa Maria, v.14, n. 2, p. 21-27, 2004.

MEYER, L.; SEVEGNANI, L.; GASPER, A.L.; VIBRANS, A.C.; LINGNER, D.V.; SOBRAL, M.G.; KLEMZ, G.; SCMDT, R.; ANASTÁCIO, C.; BRONGI, E. Fitossociologia do componente arbóreo/arbustivo da Floresta Ombrófila Mista em Santa Catarina In: VIBRANS, A.C.; SEVEGNANI, L.; GASPER, A.L.; LINGNER, D.V. (eds.). Inventário Florístico Florestal de Santa Catarina - Vol. III, Floresta Ombrófila Mista, Edifurb, Blumenau, p. 157-190, 2013.

PROCHNOW, M. (Org.) Matas Legais - Planejando Propriedades e Paisagens Apremavi, Rio do Sul, 61p., 2008.

RIBEIRO, M.C.; METZGER, J.P.; MARTENSEN, A.C.; PONZONI, F.J.; HIROTA, M.M. The Brazilian Atlantic Forest: How much is left, and how is the remaining forest distributed? Implications for conservation Biological Conservation, Cambridge, v.142, p.11411153, 2009.

ROBERTS, E.H. Predicting the storage life of seed Seed Science and Technology, Zurique, v.1, p. 499-514, 1973.

RODRIGUES RR, BRANCALION PHS, ISERNHAGEN I. (Org). Pacto pela restauração da Mata Atlântica: referencial dos conceitos e ações de restauração florestal Instituto Bioatlântica, São Paulo, 256p., 2009.

SANTOS JÚNIOR, N.A. Estabelecimento inicial de espécies florestais nativas em sistema de semeadura direta Dissertação (Mestrado em Engenharia Florestal), Universidade Federal de Lavras, Lavras, 96p. 2000.

SANTOS, P. V. Estabelecimento de espécies florestais nativas por meio de semeadura direta para recuperação de áreas degradadas Revista Árvore, Viçosa, v.36, n.2, p. 237245, 2012.

SEVEGNANI, L.; SCHROEDER, E. (Orgs.) Biodiversidade Catarinense: características, potencialidades, ameaças Edifurb, Blumenau, 252p., 2013.

SILVA, L.V.; QUEIROZ, S.E.; SILVA, M.Q.; COSTA, J.; FERNANDES, R.L. Uso de protetor físico na semeadura direta para recuperação de áreas degradadas Bioscience Journal, Uberlândia, v. 28, n. 3, p. 366-372, 2012.

SILVA, M.A.G.; MUNIZ, A.S. Exigências nutricionais de mudas de cedro (Cedrela fissilis Velloso) em solução nutritiva Revista Árvore, Viçosa, v. 19, n. 3, p. 415-425, 1995.

SOS MATA ATLÂNTICA. Disponível em: https://www.sosma.org.br/projeto/atlasda-mata-atlantica/dados-mais-recentes /. Acesso em: março de 2016.

VIBRANS, A.C.; SEVEGNANI, L.; GASPER, A.L.; LINGNER, D.V. (Ed.) Inventário Florístico Florestal de Santa Catarina - Vol. III. Floresta Ombrófila Mista Edifurb, Blumenau, 440p., 2013a. 
VIBRANS AC, MCROBERTS R. E, LINGNER DV, NICOLETTI AL, MOSER P. Extensão original e remanescentes da Floresta Ombrófila Mista em Santa Catarina In: VIBRANS, A.C.; SEVEGNANI, L.; GASPER,
A.L.; LINGNER, D.V. (eds.). Inventário Florístico Florestal de Santa Catarina - Vol. III, Floresta Ombrófila Mista, Edifurb, Blumenau, p. 25-33, 2013b. 